\title{
THE ELEMENTS OF THE OPERATOR CONVEXITY IN THE CONSTRUCTION OF THE PROGRAMMED ITERATION METHOD
}

\author{
D.A. Serkov, Krasovskii Institute of Mathematics and Mechanics, Ural Branch,
} Russian Academy of Sciences; Ural Federal University, Ekaterinburg, Russian Federation, serkov@imm.uran.ru, A.G. Chentsov, Krasovskii Institute of Mathematics and Mechanics, Ural Branch, Russian Academy of Sciences; Ural Federal University, Ekaterinburg, Russian Federation, chentsov@imm.uran.ru

The problem of retention studied here can be regarded (in the case of bounded control interval) as a variant of the approach problem within the given constraints in the phase space and the target set given by the hyperplane of the space positions corresponding to the terminal moment of the process (the retention problem on the infinite horizon also fits the problem stated in the work). The main difference of the problem from the previously considered formulation is the possibility of variation of the spaces of system trajectories and disturbance realizations depending on the initial moment of control. It is shown that the unsolvability set of the retention problem is the operator convex hull of the empty set constructed on the base of programmed absorption operator. Under some additional coherence conditions (on the spaces of system trajectories and disturbance realizations corresponding to different initial moments) the set of successful solvability is constructed as the limit of the iterative procedure in the space of sets, elements of which are positions of the game; in this case the structure of resolving quasistrategy is also given.

Keywords: programmed iterations; operator convexity; quasistrategies.

\section{Introduction}

In the works $[1,2]$ of N.N. Krasovskii and A.I. Subbotin a fundamental theorem on the alternative in nonlinear differential game has established. The result has directed the development of the differential games theory and provided the basis of effective methods of solving. This theorem determines the split of the game positions into the sum of two sets, one of which corresponds to a successful solvability of the approach problem by one player, and the second set - to a successful solvability of the evasion problem by another player. The players strive to achieve their goals using a positional strategies [1-3]. An important generalization of this theorem obtained by A.V. Kryazhimskii [4] in application to the controlled systems that are not Lipschitz with respect to phase variable.

The problem of retention studied in this work might be regarded as a variant of the approach problem within the given constraints in the phase space and the target set given by the hyperplane of the space positions corresponding to the terminal moment of the process (the retention problem on the infinite horizon also fit to the problem statement in the work). This problem, on the one hand, has a lot of applications, and on the other plays an important role in solution of the above pursuit-evasion differential games as the requirement of holding the trajectory of the controlled system within N.N. Krasovskii's stable bridge [3, §39].

In theory of differential games it is natural to use the programming constructions that define the solution in so called regular case $[2,3,5,6]$. In more general cases the idea 
of programmed control can also be implemented in solution as an iterative process. In this regard, recall the works [7-13] on the differential games for traditional controlled systems (with Lipschitz condition on the phase variable and the sub-linear growth condition on the differential equation), which dealt with a decision based on the method of programmed iterations (MPI). The above-mentioned generalization by A.V. Kryazhimskii of the alternative theorem was followed by the works on MPI for systems that satisfy more general conditions similar to those of [4]; see, in particular, [14] and several follow-up studies of one of the authors. These studies were associated with the game solution in the class of multivalued quasistrategies (see [8-10,14,15]).

It was also noted the relation of MPI and methods of the axiomatic theory of convexity [16], namely: iterative procedure [17] that is dual to MPI, admits a natural interpretation in terms of prehull operator [16, p.12]. This relation was studied in [17] for the case of "ordinary" differential games. Later (see $[18,19]$, etc.), the MPI scheme was extended to problems with abstract dynamics, including a direct version of the method (see [20-22]).

In this study, the approach [17] is extended to the abstract retention problem: on the basis of the scheme $[18,19]$ for problem of retention of trajectories in phase constraints it is constructed both direct and dual iterative procedures in the space of sets, and the latter is reduced to the construction of operator-convex hull of empty set.

The essential difference of the paper from [23] is the variability of the spaces of the system trajectories and the disturbance realizations depending on the initial moment. Nevertheless, an additional consistency condition required for construction of the resolving quasistrategy.

It is shown that the unsolvability set of the retention problem is the least element of the convexity constructed on the base of programmed absorption operator; under some additional consistency conditions (on the spaces of system trajectories and disturbances realisations corresponding to the different time moments) the result of the direct MPI procedure is the set of successful solvability of the retention problem in the space of positions of the game; for the case the structure of resolving quasistrategies is also provided. The horizon of the control problem is not assumed to be bounded; note in this connection the works $[24,25]$.

\section{General Concepts}

Common notation. Hereinafter, we use the set-theoretic symbols (quantifiers, propositional bundles, $\varnothing-$ the empty set); $\triangleq-$ equality by definition; "def" replaces the phrase "by definition". We accept the axiom of choice. The set consisting of sets is called family. If $\mathcal{Z}$ is the family of subsets $(\mathrm{s} / \mathrm{s})$ of the set $\mathbb{Z}$, then we denote by $\mathcal{C}_{\mathbb{Z}}[\mathcal{Z}]$ its dual family: $\mathcal{C}_{\mathbb{Z}}[\mathcal{Z}] \triangleq\{\mathbb{Z} \backslash Z: Z \in \mathcal{Z}\}$.

By $\mathcal{P}(T)$ (by $\mathcal{P}^{\prime}(T)$ ) we denote the family of all (all nonempty) s/s of an arbitrary set $T$; the family $\mathcal{P}(T)$ also called Boolean of the set $T$. If $A$ and $B$ are non-empty sets, then $B^{A}$ is def the set of all mappings from the set $A$ to the set $B$ (see [26]). If $f \in B^{A}$ and $C \in \mathcal{P}^{\prime}(A)$, then $(f \mid C) \in B^{C}$ is def the contraction of $f$ on the set $C:(f \mid C)(x) \triangleq f(x)$ $\forall x \in C$. In the case when $F \in \mathcal{P}^{\prime}\left(B^{A}\right)$, we denote $(F \mid C) \triangleq\{(f \mid C): f \in F\}$. If $z$ is an ordered pair, that is $z=(a, b)$ for some objects $a$ and $b$, then by $\operatorname{pr}_{1}(z)$ and $\operatorname{pr}_{2}(z)$ we denote, respectively, the first and the second elements of $z$, that are uniquely determined by the condition $z=\left(\mathbf{p r}_{1}(z), \mathbf{p r}_{2}(z)\right)$; so, it is clear, that $\mathbf{p r}_{1}(z)=a$ and 
$\operatorname{pr}_{2}(z)=b$. Let $\mathbb{N} \triangleq\{1 ; 2 ; \ldots\}$ and $\mathbb{N}_{0} \triangleq\{0\} \cup \mathbb{N}$ (then $\left.\mathbb{N}_{0}=\{0 ; 1 ; 2 ; \ldots\}\right)$. For an arbitrary set $E$, a sequence $\left(A_{i}\right)_{i \in \mathbb{N}} \in \mathcal{P}(E)^{\mathbb{N}}$ and a set $A \in \mathcal{P}(E)$ we, as usual, define $\left(\left(A_{i}\right)_{i \in \mathbb{N}} \downarrow A\right) \stackrel{\text { def }}{\Leftrightarrow}\left(\left(A=\bigcap_{i \in \mathbb{N}} A_{i}\right) \&\left(A_{j+1} \subset A_{j} \forall j \in \mathbb{N}\right)\right)$.

Elements of topology. If $(V, \tau)$ is a topological space (TS) and $Z \in \mathcal{P}(V)$, then $\left.\tau\right|_{Z} \triangleq\{Z \cap G: G \in \tau\}$ is the topology of $Z$ that realizes in the form of TS $\left(Z,\left.\tau\right|_{Z}\right)$ is the subspace of $(V, \tau)$; If $(Z, \tau)$ and $\left(Z^{\prime}, \tau^{\prime}\right)$ are TS, then $\tau \otimes \tau^{\prime}$ denotes the standard product topology of $(Z, \tau)$ and $\left(Z^{\prime}, \tau^{\prime}\right)$ (see e.g. [27, section 2.3]), the base of which consists of all rectangles $G \times G^{\prime}, G \in \tau, G^{\prime} \in \tau^{\prime}$. If $(V, \tau)$ is TS and $v \in V$, then using $\mathbf{N}_{\tau}(v)$ we refer to the filter of all neighborhoods of $v[28$, Ch. I].

Spaces with convexity. In the axiomatic theory of convexity the space with convexity corresponds to the equipment of some non-empty set by the special family of its subsets (see [16, p. 9]), that on the level of ideas is similar to the equipment by a topology. An natural example of convexity gives a family of closed sets in TS, that is, the closed topology in the terminology of P.S. Aleksandrov [29, p. 98]. Of course, the usual convexity, implemented in linear spaces, "fits" the axiomatic construction of convexity [16].

Important element of the axiomatic theory of convexity are the concepts of convex hull and prehull. It turned out [17], that MPI in dual form is completely characterized by prehull in so-called operator convexity (see [16, p. 11]). From this view point one of the sets in the above alternative partition, corresponding to the approach problem, might be presented as a convex hull of the empty set. In the paper, the presentation is extended to the case of abstract retention problem.

We recall (see [16, p. 9]) that for every nonempty sets $\mathbb{H}$ an arbitrary family $\mathcal{H} \in \mathcal{P}^{\prime}(\mathcal{P}(\mathbb{H}))$ for which $(\mathbb{H} \in \mathcal{H}) \&\left(\bigcap_{H \in \mathcal{C}} H \in \mathcal{H} \forall \mathcal{C} \in \mathcal{P}^{\prime}(\mathcal{H})\right)$ is called the convexity on $\mathbb{H}$. Using $(\mathrm{CONV})[\mathbb{H}]$ denote the set of all convexities on $\mathbb{H}$, that is

$$
(\mathrm{CONV})[\mathbb{H}] \triangleq\left\{\mathcal{H} \in \mathcal{P}^{\prime}(\mathcal{P}(\mathbb{H})) \mid(\mathbb{H} \in \mathcal{H}) \&\left(\bigcap_{H \in \mathcal{C}} H \in \mathcal{H} \forall \mathcal{C} \in \mathcal{P}^{\prime}(\mathcal{H})\right)\right\}
$$

If $\mathcal{H} \in(\mathrm{CONV})[\mathbb{H}]$, then for every set $S \in \mathcal{P}(\mathbb{H})$ the nonempty (see (1)) family $[\mathcal{H}](S) \triangleq\{H \in \mathcal{H} \mid S \subset H\}$ of all sets from $\mathcal{H}$ containing $S$, is determined and we can define the intersection

$$
(\mathcal{H}-\text { hull })[S] \triangleq \bigcap_{H \in[\mathcal{H}](S)} H \in \mathcal{P}(\mathbb{H}),
$$

that: 1) is contained in $\mathcal{H}$ (see (1)); 2) contains $S$. The set (2) will be called the convex hull of $S$. It is clear that $(\mathcal{H}-$ hull $)[S] \subset \Lambda \forall \Lambda \in[\mathcal{H}](S)$.

If $\mathcal{Q} \in \mathcal{P}^{\prime}(\mathcal{P}(\mathbb{H}))$ and $J \in \mathcal{P}(\mathbb{H})^{\mathcal{Q}}$, then we may define the corresponding $J$-operator convexity on $\mathbb{H}$ :

$$
(J-\text { conv })[\mathbb{H}] \triangleq\{A \in \mathcal{P}(\mathbb{H}) \mid \forall B \in \mathcal{Q} \quad(B \subset A) \Rightarrow(J(B) \subset A)\}
$$

according to $[16$, theorem 1.3$](J-$ conv $)[\mathbb{H}] \in(\mathrm{CONV})[\mathbb{H}]$ (the family $Q$ is the domain of definition for $J$ and, so, it is well-defined by $J$ ).

Following [16, p. 12], we introduce the notion of (convex) prehull, specifying the set

$$
\begin{aligned}
(\mathrm{p}-\mathrm{HULL})[\mathbb{H}] \triangleq\left\{g \in \mathcal{P}(\mathbb{H})^{\mathcal{P}(\mathbb{H})} \mid(E \subset g(E) \forall E \in \mathcal{P}(\mathbb{H})) \&\right. \\
\left.\quad \&\left(\forall E \in \mathcal{P}(\mathbb{H}) \forall E^{\prime} \in \mathcal{P}(\mathbb{H})\left(E \subset E^{\prime}\right) \Rightarrow\left(g(E) \subset g\left(E^{\prime}\right)\right)\right)\right\}
\end{aligned}
$$


the mappings from the set (4) are called prehulls on $\mathbb{H}$.

The definition $(3)$ can be applied for the case when $Q=\mathcal{P}(\mathbb{H})$ and $J \in(\mathrm{p}-\mathrm{HULL})[\mathbb{H}]$. According to [16, Lemma 1.1] in this case

$$
(J-\text { conv })[\mathbb{H}]=\{A \in \mathcal{P}(\mathbb{H}) \mid A=J(A)\} \quad \forall J \in(\mathrm{p}-\mathrm{HULL})[\mathbb{H}] .
$$

The Abstract Dynamic System. Hereinafter we fix a nonempty s/s $I$ of real numbers $\mathbb{R}$ as an analogue of the time interval and a nonempty set $X$ corresponding to the phase space. Let $D \triangleq I \times X$ be the set of space positions. If $t \in I$, then we define $I_{t} \triangleq$ $\{\xi \in I \mid \xi \leqslant t\}$ and $\mathbf{I}_{t} \triangleq\{\xi \in I \mid \xi \geqslant t\}$. If $t \in I$ and $\theta \in \mathbf{I}_{t}$, than $\mathbb{I}_{t}^{(\theta)} \triangleq I_{\theta} \cap \mathbf{I}_{t}$. For a nonempty set $L$ we determine Boolean $\mathcal{P}(I \times L)$ of the (nonempty) set $I \times L$ and consequently, $L^{\mathbf{I}_{t}} \in \mathcal{P}^{\prime}\left(\mathcal{P}^{\prime}(I \times L)\right.$ ) (we identify mappings from $\mathbf{I}_{t}$ into $L$ with their graphs, receiving a nonempty s/s of $I \times L)$. Thus, we have a family $\bigcup_{t \in I} L^{\mathbf{I}_{t}}$ and its Boolean. So, defined the family $\mathcal{P}^{\prime}\left(\cup_{t \in I} L^{\mathbf{I}_{t}}\right)=\mathcal{P}\left(\cup_{t \in I} L^{\mathbf{I}_{t}}\right) \backslash\{\varnothing\}$; hence, for arbitrary $\theta \in$ $I$ the relation $\mathcal{P}^{\prime}\left(\cup_{t \in I} L^{\mathbf{I}_{t}}\right) \cap \mathcal{P}^{\prime}\left(L^{\mathbf{I}_{\theta}}\right)=\mathcal{P}^{\prime}\left(L^{\mathbf{I}_{\theta}}\right)$ holds. In other words, for the set $L$ the mapping $\theta \mapsto L^{\mathbf{I}_{\theta}}: I \mapsto \mathcal{P}^{\prime}\left(\cup_{t \in I} L^{\mathbf{I}_{t}}\right)$ is defined, and, therefore, we have a nonempty set (Pack) $[L] \triangleq \prod_{\theta \in I} \mathcal{P}^{\prime}\left(L^{\mathbf{I}_{\theta}}\right)$. Fix an arbitrary nonempty set $Y$ and choose (nonempty by construction) sets $\left(\mathbf{C}_{t}\right)_{t \in I} \in($ Pack $)[X]$ and $\left(\Omega_{t}\right)_{t \in I} \in($ Pack $)[Y]$. Then for $t \in I$ we have the properties $\mathbf{C}_{t} \in \mathcal{P}^{\prime}\left(X^{\mathbf{I}_{t}}\right), \Omega_{t} \in \mathcal{P}^{\prime}\left(Y^{\mathbf{I}_{t}}\right)$; in particular, $\mathbf{C}_{t} \subset X^{\mathbf{I}_{t}}, \Omega_{t} \subset Y^{\mathbf{I}_{t}}$. A mapping from $\mathbf{I}_{t}$ into $X$ lying in $\mathbf{C}_{t}$ is considered as a trajectory for initial moment $t \in I$. The elements $\omega \in \Omega_{t}$ are considered as realisations of uncertain factors on "interval" $\mathbf{I}_{t}$. And at last, let us define as the analogue of a dynamical system the mapping (more precisely, an indexed family of mappings)

$$
\left(\mathcal{S}_{t}\right)_{t \in I} \in \prod_{t \in I} \mathcal{P}^{\prime}\left(\mathbf{C}_{t}\right)^{X \times \Omega_{t}}
$$

From (6) it follows, of course, that for $t \in I$ the operator $\mathcal{S}_{t}: X \times \Omega_{t} \mapsto \mathcal{P}^{\prime}\left(\mathbf{C}_{t}\right)$ is defined; for this operator, in its turn, the cross-section at $x \in X$ is defined as mapping $\mathcal{S}_{t}(x, \cdot)$ of the form $\omega \mapsto \mathcal{S}_{t}(x, \omega): \Omega_{t} \mapsto \mathcal{P}^{\prime}\left(\mathbf{C}_{t}\right)$. Since for $z \in D \mathbf{p r}_{1}(z) \in I$ and $\mathbf{p r}_{2}(z) \in X$, then $\mathcal{S}(z, \omega) \triangleq \mathcal{S}_{\mathbf{p r}_{1}(z)}\left(\mathbf{p r}_{2}(z), \omega\right) \in \mathcal{P}^{\prime}\left(\mathbf{C}_{t}\right)$ is defined for all $\omega \in \Omega_{t}$. Therefore, if $t \in I, x \in X$ and $\omega \in \Omega_{t}$, then we have the set

$$
\mathcal{S}((t, x), \omega) \in \mathcal{P}^{\prime}\left(\mathbf{C}_{t}\right) .
$$

So, for $z \in D$ (i.e. $z=(t, x)$, where $t \in I$ and $x \in X$ ) and $\omega \in \Omega_{t}$ the set $\mathcal{S}(z, \omega)$ outlines the trajectories of the system (7) corresponding to given initial position $z$ and the action $\omega$, where $\omega$ is specific realisation of uncertain factors on the "interval" $\mathbf{I}_{t}$. In this connection, we introduce for $t \in I$ the set $\mathbf{M}_{t} \triangleq \mathcal{P}\left(\mathbf{C}_{t}\right)^{\Omega_{t}}$ of all multi-functions (m/f) on $\Omega_{t}$ with values in $\mathbf{C}_{t}: \alpha(\omega) \subset \mathbf{C}_{t}$ for $\omega \in \Omega_{t}, \alpha \in \mathbf{M}_{t}$. Given $t \in I$ and $\alpha \in \mathbf{M}_{t}$, the $\mathrm{m} / \mathrm{f} \alpha$ is said to be non-anticipating, if for all $\omega \in \Omega_{t} \omega^{\prime} \in \Omega_{t}$ and $\xi \in \mathbf{I}_{t}$ :

$$
\left(\left(\omega \mid \mathbb{I}_{t}^{(\xi)}\right)\right)=\left(\left(\omega^{\prime} \mid \mathbb{I}_{t}^{(\xi)}\right)\right) \Rightarrow\left(\left(\alpha(\omega) \mid \mathbb{I}_{t}^{(\xi)}\right)=\left(\alpha\left(\omega^{\prime}\right) \mid \mathbb{I}_{t}^{(\xi)}\right)\right)
$$

We presume, that the control side uses for the purpose of forming trajectories nonempty valued $\mathrm{m} / \mathrm{f}$ from $\mathbf{M}_{t}$ with the property (8). Thus, when $(t, x) \in D$ the set

$$
\begin{aligned}
\mathbb{M}_{(t, x)} \triangleq\left\{\alpha \in \prod_{\omega \in \Omega_{t}} \mathcal{P}^{\prime}(\mathcal{S}((t, x), \omega)) \mid \forall \omega \in \Omega_{t} \forall \omega^{\prime} \in \Omega_{t} \forall \xi \in \mathbf{I}_{t}\right. \\
\left.\left(\left(\omega \mid \mathbb{I}_{t}^{(\xi)}\right)=\left(\omega^{\prime} \mid \mathbb{I}_{t}^{(\xi)}\right)\right) \Rightarrow\left(\left(\alpha(\omega) \mid \mathbb{I}_{t}^{(\xi)}\right)=\left(\alpha\left(\omega^{\prime}\right) \mid \mathbb{I}_{t}^{(\xi)}\right)\right)\right\}
\end{aligned}
$$


(of (multivalued) quasistrategies corresponding to the position $(t, x))$ is considered as the set of procedures acceptable for the control side. Having a particular control target, we consider it attainable for a given position $(t, x) \in D$, if there exists the quasistrategy $\alpha_{0} \in \mathbb{M}_{(t, x)}$, for which the target is achieved on each trajectory from the set $\cup_{\omega \in \Omega_{t}} \alpha_{0}(\omega)$.

We fix the topology $\tau$ on the set $X$ and postulate that $(X, \tau)$ is a $T_{2}$-space. By $\mathfrak{F}$ we denote the family of all $\mathrm{s} / \mathrm{s}$ of $X$, closed in $(X, \tau)$. The topology $\mathfrak{D}$ on the set $D$ is assumed to be the product of the topologies $\mathcal{P}(I)$ (the discrete topology on $I$ ) and $\tau:(D, \mathfrak{D}) \triangleq(D, \mathcal{P}(I) \otimes \tau)$. We agree that

$$
H\langle t\rangle \triangleq\{x \in X \mid(t, x) \in H\} \quad \forall H \in \mathcal{P}(D) \forall t \in I .
$$

In accordance with (10) for all $H \in \mathcal{P}(D)$ we have

$$
H=\{(t, x) \in D \mid x \in H\langle t\rangle\} .
$$

Using (10) and the definition of $\mathfrak{D}$, it is easy to see that the family $\mathbf{F}$ of all $\mathrm{s} / \mathrm{s}$ of $D$, that are closed in $(D, \mathfrak{D})$, admits the representation

$$
\mathbf{F}=\{F \in \mathcal{P}(D) \mid F\langle t\rangle \in \mathfrak{F} \forall t \in I\}
$$

(i.e., $\mathbf{F}$ is the family of $\mathrm{s} / \mathrm{s}$ of $D$ with cross sections closed in $(X, \tau)$ ).

For every $t \in I$ we equip the set $X^{\mathbf{I}_{t}}$ by standard topology $\otimes^{\mathbf{I}_{t}}(\tau)$ of Tikhonov's degree of TS $(X, \tau)$, provided that $\mathbf{I}_{t}$ is used as the index set. On the set $\mathbf{C}_{t}$ we define the topology $\mathfrak{C}_{t}$ of subspaces of $T_{2}$-space $\left(X^{\mathbf{I}_{t}}, \otimes^{\mathbf{I}_{t}}(\tau)\right)$, i.e. $\mathfrak{C}_{t} \triangleq\left\{\mathbf{C}_{t} \cap G: G \in \otimes^{\mathbf{I}_{t}}(\tau)\right\}$, receiving, as a result, $T_{2}$-space $\left(\mathbf{C}_{t}, \mathfrak{C}_{t}\right)$. In other words, $\left(\mathbf{C}_{t}, \mathfrak{C}_{t}\right)$ is the set $\mathbf{C}_{t}$ in the topology of point-wise convergence. Furthermore, for $t \in I$ we introduce the families $\mathbb{F}_{t}$ and $\mathfrak{K}_{t}$ of all s/s of $\mathbf{C}_{t}$, that are, respectively, closed and compact in $\mathrm{TS}\left(\mathbf{C}_{t}, \mathfrak{C}_{t}\right)$.

\section{The Programmed Absorption Operator}

If $H \in \mathcal{P}(D), z \in D$ and $\omega \in \Omega_{\mathbf{p r}_{1}(z)}$, assume that

$$
\Pi(\omega \mid z, H) \triangleq\left\{s \in \mathcal{S}(z, \omega) \mid(\xi, s(\xi)) \in H \forall \xi \in \mathbf{I}_{\mathbf{p r}_{1}(z)}\right\} .
$$

In view of (11) definition (13) can be rewritten as follows: if $t \in I$ and $x \in X$

$$
\Pi(\omega \mid(t, x), H) \triangleq\left\{s \in \mathcal{S}((t, x), \omega) \mid s(\xi) \in H\langle\xi\rangle \forall \xi \in \mathbf{I}_{t}\right\} .
$$

It is easy to check that for any $(t, x) \in D, \omega \in \Omega_{t}$ and $H \in \mathcal{P}(D)$ the equality holds

$$
\Pi(\omega \mid(t, x), H)=\Pi\left(\omega \mid(t, x), H \cap\left(\mathbf{I}_{t} \times X\right)\right) .
$$

In terms of (13) we introduce the programmed absorption operator (PAO) A : $\mathcal{P}(D) \mapsto \mathcal{P}(D)$, namely, we assume that $\forall H \in \mathcal{P}(D)$

$$
\mathbf{A}(H) \triangleq\left\{z \in H \mid \Pi(\omega \mid z, H) \neq \varnothing \forall \omega \in \Omega_{\mathbf{p r}_{1}(z)}\right\} .
$$

We consider (16) as a kind of game operator, which, however, can be associated with the system of non-game mappings: if $t \in I, \omega \in \Omega_{t}$, the operator $\mathbb{A}_{\omega}[t]: \mathcal{P}(D) \mapsto \mathcal{P}(X)$ is determined by the condition

$$
\mathbb{A}_{\omega}[t](H) \triangleq\{x \in H\langle t\rangle \mid \Pi(\omega \mid(t, x), H) \neq \varnothing\} \quad \forall H \in \mathcal{P}(D) .
$$


The relations between PAO and the family $\mathbb{A}_{\omega}[t], t \in I, \omega \in \Omega_{t}$, defined in (17), is given by the following easily verifiable statements.

Proposition 1. If $t \in I$ and $H \in \mathcal{P}(D)$, then $\mathbf{A}(H)\langle t\rangle=\bigcap_{\omega \in \Omega_{t}} \mathbb{A}_{\omega}[t](H)$.

Corollary 1. If $H \in \mathcal{P}(D)$, then $\mathbf{A}(H)=\left\{(t, x) \in D \mid x \in \bigcap_{\omega \in \Omega_{t}} \mathbb{A}_{\omega}[t](H)\right\}$.

We introduce iterations $\left(\mathbf{A}^{k}\right)_{k \in \mathbb{N}_{0}}: \mathbb{N}_{0} \mapsto \mathcal{P}(D)^{\mathcal{P}(D)}$ of the operator $\mathbf{A}$ in an ordinary way

$$
\left(\mathbf{A}^{0}(H) \triangleq H \forall H \in \mathcal{P}(D)\right) \&\left(\mathbf{A}^{k+1} \triangleq \mathbf{A} \circ \mathbf{A}^{k} \forall k \in \mathbb{N}\right) .
$$

Now define the limit operator $\stackrel{\infty}{\mathbf{A}}: \mathcal{P}(D) \mapsto \mathcal{P}(D)$, assuming that

$$
\stackrel{\infty}{\mathbf{A}}(H)=\bigcap_{k \in \mathbb{N}_{0}} \mathbf{A}^{k}(H) \quad \forall H \in \mathcal{P}(D)
$$

Proposition 2. If $F \in \mathcal{P}(D)$ and $H \in \mathcal{P}(F)$, then $(H=\mathbf{A}(H)) \Rightarrow(H \subset \stackrel{\infty}{\mathbf{A}}(F))$.

Conditions 1, 2 and 3 will be used in the following, however, every time the use of this or that condition will be specially pointed out.

Condition 1. [Closedness of value] If $t \in I, x \in X$ and $\omega \in \Omega_{t}$, then $\mathcal{S}((t, x), \omega) \in \mathbb{F}_{t}$.

Condition 2. [Closedness of graph] If $t \in I$ and $\omega \in \Omega_{t}$, then

$$
\left\{(x, h) \in X \times \mathbf{C}_{t} \mid h \in \mathcal{S}((t, x), \omega)\right\} \in \mathcal{C}_{X \times \mathbf{C}_{t}}\left[\tau \otimes \mathfrak{C}_{t}\right]
$$

Condition 3. [Precompactness of values] If $t \in I, x \in X$ and $\omega \in \Omega_{t}$, then $\exists H \in \mathbf{N}_{\tau}(x)$ $\exists K \in \mathfrak{K}_{t}: \mathcal{S}((t, y), \omega) \subset K \forall y \in H$.

Note that condition 1 is the consequence of condition 2 .

Proposition 3. Let conditions 2 and 3 are fulfilled. Then $\mathbb{A}_{\omega}[t](F) \in \mathfrak{F}$ for all $t \in I$, $\omega \in \Omega_{t}$ and $F \in \mathbf{F}$.

Propositions 1, 3 with (12) implies following corollary.

Corollary 2. Let conditions 2 and 3 are fulfilled. Then $\mathbf{A}(F) \in \mathbf{F}, \mathbf{A}^{k}(F) \in \mathbf{F}$ and $\stackrel{\infty}{\mathbf{A}}(F) \in \mathbf{F}$ for all $F \in \mathbf{F}, k \in \mathbb{N}_{0}$.

Proposition 4. Let conditions 1 and 3 are fulfilled. Then for an arbitrary $\left(\mathcal{N}_{i}\right)_{i \in \mathbb{N}} \in \mathbf{F}^{\mathbb{N}}$ and $\mathcal{N} \in \mathcal{P}(D)$ the implication holds $\left(\left(\mathcal{N}_{i}\right)_{i \in \mathbb{N}} \downarrow \mathcal{N}\right) \Rightarrow\left(\left(\stackrel{\infty}{\mathbf{A}}\left(\mathcal{N}_{i}\right)\right)_{i \in \mathbb{N}} \downarrow \stackrel{\infty}{\mathbf{A}}(\mathcal{N})\right)$.

The proof of the proposition begins with verifying the sequential continuity of the operator $\mathbb{A}_{\omega}[t]:\left(\left(F_{i}\right)_{i \in \mathbb{N}} \downarrow F\right) \Rightarrow\left(\left(\mathbb{A}_{\omega}[t]\left(F_{i}\right)\right)_{i \in \mathbb{N}} \downarrow \mathbb{A}_{\omega}[t](F)\right.$ for all $t \in I$ and $\left.\omega \in \Omega_{t}\right)$. Then, taking into account propositions 2 , we get the sequential continuity of the operator $\mathbf{A}:\left(\left(F_{i}\right)_{i \in \mathbb{N}} \downarrow F\right) \Rightarrow\left(\left(\mathbf{A}\left(F_{i}\right)\right)_{i \in \mathbb{N}} \downarrow \mathbf{A}(F)\right)$. This property ensures, sequential continuity of the operators $\mathbf{A}^{k}, k \in \mathbb{N}$ and, consequently, their limit - operator $\stackrel{\infty}{\mathbf{A}}$.

The corollary 2 and proposition 4 provide the main property of the operator $\stackrel{\infty}{\mathbf{A}}$.

Proposition 5. Let conditions 2, 3 are fulfilled and $F \in \mathbf{F}$. Then $\mathbf{A}(\stackrel{\infty}{\mathbf{A}}(F))=\stackrel{\infty}{\mathbf{A}}(F)$. 
As a consequence, under conditions $2,3, F \in \mathbf{F}$ and $H \in \mathcal{P}(F)$ the inclusion holds $(\stackrel{\infty}{\mathbf{A}}(F) \subset H) \Rightarrow(\stackrel{\infty}{\mathbf{A}}(F)=\stackrel{\infty}{\mathbf{A}}(H))$.

\section{Connection with the Operator Convexity}

Everywhere further we fix a set $\mathcal{N} \in \mathcal{P}(D)$ (in the context of retaining problem the set $\mathcal{N}$ is used as a phase restriction). We consider the operator $\mathcal{A}: \mathcal{P}(\mathcal{N}) \mapsto \mathcal{P}(\mathcal{N})$ defined as follows

$$
\mathcal{A}(H) \triangleq \mathcal{N} \backslash \mathbf{A}(\mathcal{N} \backslash H) \quad \forall H \in \mathcal{P}(\mathcal{N}) .
$$

In connection with (20) consider the family

$$
(\mathcal{A} \text {-conv })[\mathcal{N}] \triangleq\{H \in \mathcal{P}(\mathcal{N}) \mid \forall B \in \mathcal{P}(\mathcal{N})(B \subset H) \Rightarrow(\mathcal{A}(B) \subset H)\},
$$

that provide (see $(3))$ the corresponding operator convexity: $(\mathcal{A}$-conv $)[\mathcal{N}] \in(\mathrm{CONV})[\mathcal{N}]$.

Proposition 6. The operator $\mathcal{A}$ is prehull: $\mathcal{A} \in(\mathrm{p}-\mathrm{HULL})[\mathcal{N}]$.

The proof follows from (20) and evident properties of the operator A; see also (4).

From propositions 6 in virtue of [16, Lemma 1.1] (see (5)) it follows that $(\mathcal{A}$-conv $)[\mathcal{N}]=\{H \in \mathcal{P}(\mathcal{N}) \mid \mathcal{A}(H)=H)\}$. We define the convex hull in the convexity $(\mathcal{A}$-conv $)[\mathcal{N}]$ for any $S \in \mathcal{P}(\mathcal{N})$ following $(2)$ :

$$
((\mathcal{A}-\text { conv })[\mathcal{N}]-\text { hull })[S]=\bigcap_{H \in[(\mathcal{A}-\text { conv })[\mathcal{N}]](S)} H \in(\mathcal{A}-\text { conv })[\mathcal{N}] .
$$

The next assertions are consistent with [17] in the case of positional differential games. In this regard, recall that $\stackrel{\infty}{\mathbf{A}}(\mathcal{N}) \in \mathcal{P}(\mathcal{N})$ (see (18), (19)).

In the rest of this section and in the next one we assume that $\mathcal{N} \in \mathbf{F}$.

The proposition 5 and definition (20) implies

Proposition 7. Let conditions 2 and 3 are fulfilled. Then $\mathcal{N} \backslash \stackrel{\infty}{\mathbf{A}}(\mathcal{N}) \in(\mathcal{A}$-conv $)[\mathcal{N}]$.

Note that (21) is defined also for $S=\varnothing$. From propositions 7 it follows that (see (2)) $((\mathcal{A}-$ conv $)[\mathcal{N}]-$ hull $)[\varnothing] \subset \mathcal{N} \backslash \stackrel{\infty}{\mathbf{A}}(\mathcal{N})$. Taking into account the proposals 2 and 7 verified

Theorem 1. If conditions 2 and 3 hold, then $((\mathcal{A}-$ conv $)[\mathcal{N}]-$ hull $)[\varnothing]=\mathcal{N} \backslash \stackrel{\infty}{\mathbf{A}}(\mathcal{N})$.

Corollary 3. If conditions 2 and 3 are true, then $\mathcal{N} \backslash \stackrel{\infty}{\mathbf{A}}(\mathcal{N})$ is the least element of convexity $(\mathcal{A}$-conv $)[\mathcal{N}]$. In particular,

$$
(H \in \mathcal{P}(\mathcal{N} \backslash \stackrel{\infty}{\mathbf{A}}(\mathcal{N}))) \Rightarrow(((\mathcal{A}-\text { conv })[\mathcal{N}]-\text { hull })[H]=\mathcal{N} \backslash \stackrel{\infty}{\mathbf{A}}(\mathcal{N}))
$$

\section{Coherence of the Spaces Packages and the Solvability in Quasistrategies}

Recall that in the above there were no suppositions on any consistency of the sets $\mathbf{C}_{t_{1}}$, $\mathbf{C}_{t_{2}}$ for arbitrary $t_{1} \in I, t_{2} \in I, t_{1} \neq t_{2}$. The same is true for the sets $\Omega_{t}, t \in I$. In this paragraph we assume that for any $t \in I, t^{\prime} \in \mathbf{I}_{t}$

$$
\mathbf{C}_{t^{\prime}}=\left\{\left(h \mid \mathbf{I}_{t^{\prime}}\right): h \in \mathbf{C}_{t}\right\}, \quad \Omega_{t^{\prime}}=\left\{\left(\omega \mid \mathbf{I}_{t^{\prime}}\right): \omega \in \Omega_{t}\right\}
$$


Some kind of the semi-group property will be used; in this regard, note that due to (22) for $t \in I, \omega \in \Omega_{t}, t^{\prime} \in \mathbf{I}_{t}$ and $x^{\prime} \in X$ the set $\mathcal{S}\left(\left(t^{\prime}, x^{\prime}\right),\left(\omega \mid \mathbf{I}_{t^{\prime}}\right)\right) \in \mathcal{P}^{\prime}\left(\mathbf{C}_{t^{\prime}}\right)$ is well defined.

Condition 4. [Semi-group property] $\left(h \mid \mathbf{I}_{t^{\prime}}\right) \in \mathcal{S}\left(\left(t^{\prime}, h\left(t^{\prime}\right)\right),\left(\omega \mid \mathbf{I}_{t^{\prime}}\right)\right)$ for all $(t, x) \in D$, $\omega \in \Omega_{t}, h \in \mathcal{S}((t, x), \omega)$, and $t^{\prime} \in \mathbf{I}_{t}$.

Proposition 8. If condition 4 holds, then for any $t_{*} \in I, \omega_{*} \in \Omega_{t_{*}}$ and $H \in \mathcal{P}(D)$ the equality $\mathbb{A}_{\omega_{*}}\left[t_{*}\right](H)=\mathbb{A}_{\omega_{*}}\left[t_{*}\right]\left(\left\{(t, x) \in \mathbf{I}_{t_{*}} \times X \mid x \in \mathbb{A}_{\left(\omega_{*} \mid \mathbf{I}_{t}\right)}[t](H)\right\}\right)$ is fulfilled.

Proposition 9. Let condition 4 is true. Then for any $N \in \mathcal{P}(D)$ and $F \in \mathcal{P}(N)$

$$
(F=\mathbf{A}(F)) \Leftrightarrow\left(\exists H \in \mathcal{P}(N): F\langle t\rangle=\mathbb{A}_{\omega}[t](H) \forall t \in I \forall \omega \in \Omega_{t}\right) .
$$

Consider the retaining problem in the class of multivalued quasistrategy, keeping in mind the constructions [18]. Hereinafter, for arbitrary $t \in I, t^{\prime} \in \mathbf{I}_{t}, h \in \mathbf{C}_{t}$ and $h^{\prime} \in \mathbf{C}_{t^{\prime}}$ the map $h \square h^{\prime}: \mathbf{I}_{t} \mapsto X$ (splice of $h$ and $\left.h^{\prime}\right)$ is defined by $\left(\left(h \square h^{\prime}\right)(\xi) \triangleq h(\xi)\right.$ $\left.\forall \xi \in \mathbb{I}_{t}^{\left(t^{\prime}\right)}\right) \&\left(\left(h \square h^{\prime}\right)(\zeta) \triangleq h^{\prime}(\zeta) \forall \zeta \in \mathbf{I}_{t^{\prime}} \backslash\left\{t^{\prime}\right\}\right)$.

Condition 5. [Admissibility of movements splice] For $(t, x) \in D, t^{\prime} \in \mathbf{I}_{t}$ and $\omega, \omega^{\prime} \in \Omega_{t}$ :

$\left(\left(\omega \mid \mathbb{I}_{t}^{\left(t^{\prime}\right)}\right)=\left(\omega^{\prime} \mid \mathbb{I}_{t}^{\left(t^{\prime}\right)}\right)\right) \Rightarrow\left(h \square h^{\prime} \in \mathcal{S}\left((t, x), \omega^{\prime}\right) \forall h \in \mathcal{S}((t, x), \omega) \forall h^{\prime} \in \mathcal{S}\left(\left(t^{\prime}, h\left(t^{\prime}\right)\right),\left(\omega^{\prime} \mid \mathbf{I}_{t^{\prime}}\right)\right)\right)$

Note that the next statement doesn't use defined below condition 6 of disturbances splice admissibility. This expands the statement range of use including, in particular, practically important case of "continuous" disturbances.

Proposition 10. If conditions 2, 3 and 5 are true, then $\Pi(\cdot \mid z, \stackrel{\infty}{\mathbf{A}}(\mathcal{N})) \in \mathbb{M}_{z} \forall z \in \stackrel{\infty}{\mathbf{A}}(\mathcal{N})$.

The proof of the statement is based on propositions 5 .

According to proposition 10 and definition (13) we have

$$
(t, s(t)) \in \stackrel{\infty}{\mathbf{A}}(\mathcal{N}) \quad \forall z \in \stackrel{\infty}{\mathbf{A}}(\mathcal{N}) \forall \omega \in \Omega_{\mathbf{p r}_{1}(z)} \forall s \in \Pi(\omega \mid z, \stackrel{\infty}{\mathbf{A}}(\mathcal{N})) \forall t \in \mathbf{I}_{\mathbf{p r}_{1}(z)}
$$

From (18), (19) and (23) it follows that $(t, s(t)) \in \mathcal{N}$ for all $z \in \stackrel{\infty}{\mathbf{A}}(\mathcal{N}), \omega \in \Omega_{\mathbf{p r}_{1}(z)}$, $s \in \Pi(\omega \mid z, \stackrel{\infty}{\mathbf{A}}(\mathcal{N}))$ and $t \in \mathbf{I}_{\mathbf{p r}_{1}(z)}$. Thus, for $z \in \stackrel{\infty}{\mathbf{A}}(\mathcal{N})$ we have got the explicit form of quasistrategy, resolving the problem of movements retaining in the set $\mathcal{N}$.

For arbitrary $t \in I, t^{\prime} \in \mathbf{I}_{t}, \omega \in \Omega_{t}$ and $\omega^{\prime} \in \Omega_{t^{\prime}}$ the map $\omega \diamond \omega^{\prime}: \mathbf{I}_{t} \mapsto Y$ (splice of $\omega$ and $\left.\omega^{\prime}\right)$ is defined by $\left(\left(\omega \diamond \omega^{\prime}\right)(\xi) \triangleq \omega(\xi) \forall \xi \in \mathbb{I}_{t}^{\left(t^{\prime}\right)}\right) \&\left(\left(\omega \diamond \omega^{\prime}\right)(\zeta) \triangleq \omega^{\prime}(\zeta) \forall \zeta \in \mathbf{I}_{t^{\prime}} \backslash\left\{t^{\prime}\right\}\right)$.

Condition 6. [Admissibility of disturbance splice] $\omega \diamond \omega^{\prime} \in \Omega_{t}$ for all $t \in I, t^{\prime} \in \mathbf{I}_{t}, \omega \in \Omega_{t}$ and $\omega^{\prime} \in \Omega_{t}$.

The proof of the next theorem is similar to that in $[18,23]$.

Theorem 2. Let conditions $2-6$ are fulfilled. Then the equality holds:

$$
\stackrel{\infty}{\mathbf{A}}(\mathcal{N})=\left\{z \in \mathcal{N} \mid \exists \alpha \in \mathbb{M}_{z}:(t, s(t)) \in \mathcal{N} \forall t \in \mathbf{I}_{\mathbf{p r}_{1}(z)} \forall \omega \in \Omega_{\mathbf{p r}_{1}(z)} \forall s \in \alpha(\omega)\right\} .
$$

Acknowledgements. The work was supported by Russian foundation for basic research (grants No. 16-01-00649, No. 16-01-00505) and the decision No. 211 of the Russian Government, the contract No. 02.A03.21.0006. 


\section{References}

1. Krasovskii N.N., Subbotin A.I. An Alternative for the Game Problem of Convergence. Journal of Applied Mathematics and Mechanics, 1970, vol. 34, no. 6, pp. 948-965. DOI: 10.1016/00218928(70)90158-9

2. Krasovskii N.N., Subbotin A.I. Game-Theoretical Control Problems. N.Y., Springer, 1988. $517 \mathrm{p}$.

3. Krasovskii N.N. Igrovye zadachi o vstreche dvizhenii [Game Problems on Motions Encounter]. Moscow, Nauka, 1970. 420 p.

4. Kryazhimskii A.V. [On the Theory of Positional Differential Games of Approach-Evasion]. Doklady Akademii Nauk SSSR, 1978, vol. 239, no. 4, pp. 779-782. (in Russian)

5. Krasovskii N.N. [Differential Game of Pursuit-Evasion. I]. Izvestiya Akademii Nauk SSSR. Tekhnicheskaya Kibernetika, 1973, no. 2, pp. 3-18. (in Russian)

6. Krasovskii N.N. [Differential Game of Pursuit-Evasion. II]. Izvestiya Akademii Nauk SSSR. Tekhnicheskaya Kibernetika, 1973, no. 3, pp. 22-42. (in Russian)

7. Chentsov A.G. [On the Structure of an Approach Problem]. Doklady Akademii Nauk SSSR, 1975, vol. 224, no. 6, pp. 1272-1275. (in Russian)

8. Chentsov A.G. On a Game Problem of Converging at a Given Instant of Time. Mathematics of the USSR-Sbornik, 1976, vol. 28, no. 3, pp. 353-376. DOI: 10.1070/SM1976v028n03ABEH001657

9. Chentsov A.G. On a Game Problem of Guidance. Soviet Mathematics - Doklady, 1976, vol. 17, pp. $73-77$.

10. Chentsov A.G. On a Game Problem of Guidance with Information Memory. Soviet Mathematics - Doklady, 1976, vol. 17, pp. 411-414.

11. Chistyakov S.V. On Solving Pursuit Game Problems. Journal of Applied Mathematics, 1977, vol. 41, no. 5, pp. 845-852. DOI: 10.1016/0021-8928(77)90167-8

12. Ukhobotov V.I. Construction of a Stable Bridge for a Class of Linear Games. Journal of Applied Mathematics, 1977, vol. 41, no. 2, pp. 350-354. DOI: 10.1016/0021-8928(77)90021-1

13. Melikyan A.A. The Value of a Game in a Linear Differential Game of Convergence. Soviet Mathematics - Doklady, 1977, vol. 18, pp. 1457-1461.

14. Chentsov A.G. The Programmed Iteration Method for a Differential Pursuit-Evasion Game. Dep. in VINITI, no. 1933-79, Sverdlovsk, 1979. (in Russian)

15. Chentsov A.G. [About Alternatives in the Class of Quasistrategies for Differential Games of Approach-Evasion], Differentsial'nye uravneniya [Differential equations], 1980, vol. 16, no. 10, pp. 1801-1808. (in Russian)

16. Soltan V.P. Vvedenie v aksiomaticheskuyu teoriyu vypuklosti [Introduction to Axiomatic Theory of Convexity]. Chisinau, Shtinnitsa, 1984. 224 p.

17. Chentsov A.G. On the Problem of Control with a Limited Number of Switching. Dep. in VINITI, no. 4942-B 87, Sverdlovsk, 1987. (in Russian)

18. Chentsov A.G. An Abstract Confinement Problem: a Programmed Iterations Method of Solution. Automation and Remote Control, 2004, vol. 65, no. 2, pp. 299-310. DOI: 10.1023/B:AURC.0000014727.63912.45

19. Chentsov A.G. On Interrelations Between Different Versions of the Method of Program Iterations: A Positional Version. Cybernetics and Systems Analysis, 2002, vol. 38, no. 3, pp. 422-438. DOI: $10.1023 / \mathrm{A}: 1020368828661$ 
20. Chentsov A.G. On the Iterative Realization of Nonanticipating Multivalued Mappings. Russian Mathematics, 2000, vol. 44, no. 3, pp. 63-73.

21. Chentsov A.G. Nonanticipating Multimappings and Their Construction by the Method of Program Iterations: I. Differential equations, 2001, vol. 37, no. 4, pp. 498-509. DOI: $10.1023 / \mathrm{A}: 1019275422741$

22. Chentsov A.G. Nonanticipating Multimappings and Their Construction by the Method of Program Iterations: II. Differential equations, 2001, vol. 37, no. 5, pp. 713-723. DOI: $10.1023 / \mathrm{A}: 1019224800877$

23. Serkov D.A., Chentsov A.G. [Programmed Iteration Method and Operator Convexity in an Abstract Retention Problem]. Vestnik Udmurtskogo Universiteta. Matematika. Mekhanika. Komp'yuternye Nauki, 2015, vol. 25, no. 3, pp. 348-366. (in Russian) DOI: $10.20537 / \mathrm{vm} 150305$

24. Dyatlov V.P., Chentsov A.G. Monotone Iterations of Sets and Their Applications to Game Control Problems. Kibernetika, 1987, vol. 23, no. 2, pp. 92-99.

25. Ivanov V.M., Chentsov A.G. On the Control of Discrete Systems on an Infinite Time Interval. USSR Computational Mathematics and Mathematical Physics, 1987, vol. 27, no. 6, pp. 116-121. DOI: 10.1016/0041-5553(87)90201-1

26. Kuratowski K., Mostowski A. Set Theory. Amsterdam, North-Holland Publishing Company, 1967.

27. Engelking R. General Topology. Państwowe Wydawnictwo Naukowe, Warszawa, 1977.

28. Bourbaki N. Topologie générale. Chapitre 1,2. Quatrième édition. Paris, Hermann, 1965. (in French)

29. Aleksandrov P.S. Vvedeniye v teoriyu mnoghestv i obshchuyu topologiyu [Introduction to the Sets Theory of and General Topology]. Moscow, URSS, 2004.

Received May 10, 2016

УДК 517.977

DOI: $10.14529 / \mathrm{mmp} 160307$

\section{ЭЛЕМЕНТЫ ОПЕРАТОРНОЙ ВЫПУКЛОСТИ В КОНСТРУКЦИЯХ МЕТОДА ПРОГРАММНЫХ ИТЕРАЦИЙ}

\section{Д.А. Серков, А.Г. Ченцов}

Рассматриваемая игровая задача удержания (в случае ограниченного промежутка управления) является частным случаем задачи сближения при наличии фазовых ограничений с гиперплоскостью отвечающей терминальному моменту времени (вместе с тем, задача удержания с бесконечным горизонтом также вкладывается предлагаемую постановку). Основным отличием от ранее рассмотренных постановок задачи является возможность вариации пространства траекторий системы и пространства реализаций неопределенных факторов в зависимости от начального момента управления. Показано, что множество начальных позиций, для которых задача не разрешима есть операторно-выпуклая оболочка пустого множества, построенная на основе опрератора программного поглощения. При дополнительных условиях согласованности (пространств траекторий системы и реализаций помехи в различные моменты времени) показано, что множество успешной разрешимости задачи удержания определяется в виде предела итерационной процедуры на пространстве множеств, элементами которых являются позиции игры, а также установлена структура разрешающих квазистратегий.

Ключевые слова: программные итерации; операторная выпуклость; квазистратегии. 
Работа проводиласв при финансовой поддержке Российского фонда фундаментальных исследований (проекты № 16-01-00649, № 16-01-00505) и постановления № 211 Правительства Российской Федерации, контракт № 02.A03.21.0006.

\section{Литература}

1. Красовский, Н.Н. Альтернатива для игровой задачи сближения / Н.Н. Красовский, А.И. Субботин // Прикладная математика и механика. - 1970. - Т. 34, № 6. - С. 10051022 .

2. Красовский, Н.Н. Позиционные дифференциальные игры / Н.Н. Красовский, А.И. Субботин. - М.: Наука, 1974. - 456 с.

3. Красовский, Н.Н. Игровые задачи о встрече движений / Н.Н. Красовский. - М.: Наука, 1970. -420 c.

4. Кряжимский, А.В. К теории позиционных дифференциальных игр сближенияуклонения / А.В. Кряжимский // Доклады Академии наук СССР. - 1978. - Т. 239, № 4. - С. $779-782$.

5. Красовский, Н.Н. Дифференциальная игра сближения-уклонения. I / Н.Н. Красовский // Известия Академии наук СССР: Техническая кибернетика. - 1973. - № 2. C. $3-18$.

6. Красовский, Н.Н. Дифференциальная игра сближения-уклонения. II / Н.Н. Красовский // Известия Академии наук СССР: Техническая кибернетика. - 1973. - № 3. C. $22-42$.

7. Ченцов, А.Г. О структуре одной игровой задачи сближения / А.Г. Ченцов // Доклады Академии наук СССР. - 1975. - Т. 224, № 6. - С. 1272-1275.

8. Ченцов, А.Г. Об игровой задаче сближения в заданный момент времени / А.Г. Ченцов // Математический сборник. - 1976. - Т. 99 (141), № 3. - С. 394-420.

9. Ченцов, А.Г. К игровой задаче наведения / А.Г. Ченцов // Доклады Академии наук CCCP. - 1976. - T. 226 , № 1. - С. $73-76$.

10. Ченцов, А.Г. К игровой задаче наведения с информационной памятью / А.Г. Ченцов // Доклады Академии наук СССР. - 1976. - Т. 227, № 2. - С. 306-309.

11. Чистяков, С.В. К решению игровых задач преследования / С.В. Чистяков // Прикладная математика и механика. - 1977. - Т. 41, № 5. - С. 825-832.

12. Ухоботов, В.И. Построение стабильного моста для одного класса линейных игр / В.И. Ухоботов // Прикладная математика и механика. - 1977. - Т. 41, № 2. - С. 358-364.

13. Меликян, А.А. Цена игры в линейной дифференциальной игре сближения / А.А. Меликян // Доклады Академии наук СССР. - 1977. - Т. 237, № 3. - С. 521-524.

14. Ченцов, А.Г. Метод программных итераций для дифференциальной игры сближенияуклонения: Рукопись депонирована в ВИНИТИ: 1933-79 Деп. / А.Г. Ченцов. - Свердловск: Уральский политехнический институт им. С.М. Кирова, 1979.

15. Ченцов, А.Г. Об альтернативе в классе квазистратегий для дифференциальной игры сближения-уклонения / А.Г. Ченцов // Дифференциальные уравнения. - 1980. - Т. 16, № 10. - C. 1801-1808.

16. Солтан, В.П. Введение в аксиоматическую теорию выпуклости / В.П. Солтан. - Кишинев: Штинница, 1984. - 224 с. 
17. Ченцов, А.Г. О задаче управления с ограниченным числом переключений: депонированная рукопись: 4942-В 87 / А.Г. Ченцов. - Свердловск: Уральский политехнический институт им. С.М. Кирова, 1987.

18. Ченцов А.Г. Метод программных итераций для решения абстрактной задачи удержания / А.Г. Ченцов // Автоматика и телемеханика. - 2004. - № 2. - С. 157-169.

19. Ченцов, А.Г. K вопросу о соотношении различных версий метода программных итераций: позиционный вариант / А.Г. Ченцов // Кибернетика и системный анализ. - 2002. - № 3. - С. 130-149.

20. Ченцов А.Г. К вопросу об итерационной реализации неупреждающих многозначных отображений / А.Г. Ченцов // Известия ВУЗов. Математика. - 2000. - № 3. - С. 66-76.

21. Ченцов А.Г. Неупреждающие многозначные отображения и их построение с помощью метода программных итераций. I / А.Г. Ченцов // Дифференциальные уравнения. 2001. - Т. 37, № 4. - C. 470-480.

22. Ченцов А.Г. Неупреждающие многозначные отображения и их построение с помощью метода программных итераций. II / А.Г. Ченцов // Дифференциальные уравнения. 2001. - Т. 37, № 5. - С. 679-688.

23. Серков, Д.А. Метод программных итераций и операторная выпуклость в абстрактной задаче удержания / Д.А. Серков, А.Г. Ченцов // Вестник Удмуртского университета. Серия 1: Математика. Механика. Компьютерные науки. - 2015. - Т. 25, № 3. - С. 348-366.

24. Ченцов, А.Г. Монотонные итерации множеств и их приложения к игровым задачам управления / А.Г. Ченцов, В.П. Дятлов // Кибернетика. - 1987. - № 2. - С. 92-99.

25. Иванов, В.М. Об управлении дискретными системами на бесконечном промежутке времени / В.М. Иванов, А.Г. Ченцов // Журнал вычислительной математики и математической физики. - 1987. - Т. 27, № 12. - С. 1780-1789.

26. Куратовский, К. Теория множеств / К. Куратовский, А. Мостовский. - М.: Мир, 1970. $-416 \mathrm{c}$.

27. Энгелькинг, Р. Общая топология / Р. Энгелькинг. - М.: Мир, 1986. - 752 с.

28. Бурбаки, Н. Общая топология. Основные структуры / Н. Бурбаки. - М.: Наука, 1968. $275 \mathrm{c}$.

29. Александров, П.С. Введение в теорию множеств и общую топологию / П.С. Александров. - М.: Едиториал УРСС, 2004. - 367 с.

Дмитрий Александрович Серков, доктор физико-математических наук, ведущий научный сотрудник, Институт математики и механики им. Н.Н. Красовского УрО РАН; профессор, кафедра вычислительных методов и уравнений математической физики, Институт радиоэлектроники и информационных технологий, Уральский федеральный университет им. первого Президента России Б.Н. Ельцина (г. Екатеринбург, Российская Федерация), serkov@imm.uran.ru.

Александр Георгиевич Ченцов, доктор физико-математических наук, членкорреспондент РАН, главный научный сотрудник, Институт математики и механики им. Н.Н. Красовского УрО РАН; профессор, кафедра вычислительных методов и уравнений математической физики, Институт радиоэлектроники и информационных технологий, Уральский федеральный университет им. первого Президента России Б.Н. Ельцина (г. Екатеринбург, Российская Федерация), chentsov@imm.uran.ru.

Поступила в редакиию 10 мая 2016 г. 